This item was submitted to Loughborough's Research Repository by the author.

Items in Figshare are protected by copyright, with all rights reserved, unless otherwise indicated.

\title{
A comparison of four modelling techniques for thermoelectric generator
}

\section{PLEASE CITE THE PUBLISHED VERSION}

https://doi.org/10.4271/2017-01-0144

\section{PUBLISHER}

(C) SAE International

\section{VERSION}

AM (Accepted Manuscript)

\section{PUBLISHER STATEMENT}

This work is made available according to the conditions of the Creative Commons Attribution-NonCommercialNoDerivatives 4.0 International (CC BY-NC-ND 4.0) licence. Full details of this licence are available at: https://creativecommons.org/licenses/by-nc-nd/4.0/

\section{LICENCE}

CC BY-NC-ND 4.0

\section{REPOSITORY RECORD}

Yang, Zhijia, Song Lan, Richard Stobart, Edward Winward, Rui Chen, and lain Harber. 2017. "A Comparison of Four Modelling Techniques for Thermoelectric Generator". figshare. https://hdl.handle.net/2134/24130. 


\title{
A Comparison of Four Modelling Techniques for Thermoelectric Generator
}

\author{
Author, co-author (Do NOT enter this information. It will be pulled from participant tab in \\ MyTechZone) \\ Affiliation (Do NOT enter this information. It will be pulled from participant tab in MyTechZone)
}

\begin{abstract}
The application of state-of-art thermoelectric generator (TEG) in automotive engine has potential to reduce more than $2 \%$ fuel consumption and hence the $\mathrm{CO}_{2}$ emissions. This figure is expected to be increased to 5\% 10\% in the near future when new thermoelectric material with higher properties is fabricated. However, in order to maximize the TEG output power, there are a few issues need to be considered in the design stage such as the number of modules, the connection of modules, the geometry of the thermoelectric module, the DC-DC converter circuit, the geometry of the heat exchanger especially the hot side heat exchanger etc. These issues can only be investigated via a proper TEG model. The authors introduced four ways of TEG modelling which in the increasing complexity order are MATLB function based model, MATLAB Simscape based Simulink model, GT-power TEG model and CFD STAR-CCM+ model. Both Simscape model and GT-Power model have intrinsic dynamic model performance. MATLAB function based model and STAR-CCM+ model can be developed to have only steady state performance or to include dynamic performance. Steady state model can be used in quick assessment of TEG performance and for initial design optimization. However, only dynamic model can give the accurate prediction of TEG output during engine transient cycles. This paper also demonstrates finding the answers to three TEG related questions using STAR-CCM+, Simscape and MATLAB function based Simulink model respectively.
\end{abstract}

\section{Introduction}

Thermoelectric device is a bi-direction energy converter between thermal energy and electrical energy. When there is thermal gradient developed across a couple which is consisted of one n-type leg and one p-type leg, this couple will work as a small voltage battery which is Seebeck mode. On the other hand, if an external voltage applied to the two terminals of the couple, there will be heat be pumped from one end of the legs to the other end of the legs though the legs. This is known as Peltier mode [1]. This reversible energy conversion property makes the thermoelectric device have big potential for being an actuator in future thermal management systems in vehicle other than working only in uni-function, either Thermoelectric Generator (TEG) for thermal energy harvest or Thermoelectric Cooler (TEC) for heating, refrigerator and air-conditioner. For example, it can be used in heating battery, catalyst, fuel, oil and engine coolant up before engine cold start and then it can harvest the thermal energy when the engine works in warm and heavy load condition. This will provide another control freedom in the online optimization of the whole vehicle system in fuel consumption and $\mathrm{CO}_{2}$ emissions. The very open prediction for the future could be that most thermal sensitive components and the whole engine surface together with the exhaust system in the vehicle will possibly be wrapped or integrated with thermoelectric layers.

So far, in the domain of automotive application, the majority research efforts are focused on the optimization and prediction of the TEG performance and the reduction of the device cost related to the waste thermal energy harvest in both diesel and gasoline engines [2 9]. The optimization and prediction work unavoidably has to be based on device and system level model. There are multiple choices of modelling technique or environment for doing both the device and system level modelling work. If the hot side and cold side temperature is equally distributed, the basic equations for Seebeck, Peltier, Thomas effect and energy conservative of one thermoelectric module (TEM) can be clearly stated and be numerically calculated using Excel, calculator, Fortran or C language or MATLAB scripts. However, there will be numbers of TEMs in a TEG used in engine exhaust waste energy harvest and the boundary conditions for each TEM are not the same. Hence, the modelling of a TEG device needs proper software environment.

Since the TEG device has both thermal and electrical mechanism and the thermal phenomenon can be modelled as equivalent electric circuit, the electric circuit and analysis software SPICE can be used for modelling the TEG device [10,11]. The temperature depended properties of the thermoelectric material can be modelled using polynomial function within the circuit block. But this type of model is purely steady state. If the TEG model needs to be coupled to engine model, MATLAB/Simulink, Simscape or GT-Power can be chosen as the modelling environment. They all can model the TEG dynamic behaviour. Simscape has both fundamental thermal and electrical elements. A physical TEG model together with DC/DC converter circuit can be built up based on the physical connections of thermal and electrical elements [12]. A Simscape TEG model can run directly within Simullink model frame. If the engine model is also a Simscape model or a Mean Value Engine Model (MVEM) developed in Simulink environment, there will be seamless integration of TEG model with engine model. In 2016b version of MATLAB, other than electrical and thermal elements, there are elements for gas system which make the modelling of engine exhaust system more convenient. GT-power is a commonly used software for engine modelling. There is also a TEM block in the GT-Power library in later than 2013 version. The development of one TEM unit model is quite straightforward using GT-power [13]. The analysis of heat flux, stress, pressure drop, heat exchanger performance is best to be carried out using 3D CAD and CFD modelling techniques $[3,4,14,15]$.

Page 1 of 12

$10 / 19 / 2016$ 
This paper presents the applications of four modelling techniques in solving TEG related optimization problem or questions. It is organized as this: In section 2, STAR-CCM+ was used in the analysis of the TEG performance improved using Aluminium plate between the hot side stainless heat exchanger and the TEMs. In section 3, Simscape exhaust system model was developed and validated against engine test data. This model then was used to demonstrate that only stainless pipe without inner fins will not give acceptable TEG output performance. The development of TEG GT-power model and its validation was discussed in Section 4. Then it was followed by the introduction of a Simulink dynamic TEG model which is based on MATLAB function block. This model was also validated against engine transient cycle and was used to explore the impact of thermal inertia on the TEG performance.

\section{STAR-CCM+ TEG Model}

\section{TEG Engine Test Result w/o Aluminum Plate}

Since the maximum exhaust gas temperature is normal higher than $500^{\circ} \mathrm{C}$, the hot side heat exchanger for TEG device is made from stainless steel which has as low as $16 \mathrm{~W} / \mathrm{m}$.K thermal conductivity. It can be expected that the temperature distribution within the TEM contact surface with the hot side heat exchanger surface will be very uneven. This prediction was proved by the experiment results. Figure 1 shows a TEG device with four commercial TEMs was tested in a diesel engine Exhaust Gas Recirculation (EGR) path. The sandwich assembly of this TEG device is displayed in Figure 2. Two test data set were collected at the same gas in conditions and the same clamping force. One is without aluminium plates, one is with adding two $3 \mathrm{~mm}$ aluminium plates. For the case with aluminium plates, one aluminium plate was placed between the two top TEMs and the top surface of hot side exchanger and the other was placed between the two bottom TEMs and the bottom surface of the hot side exchanger. The width and length of the aluminium plates are the same to those of the hot side surface of the hot side heat exchanger. These four TEMs were wired together electrically in series and with an external PWM current sweep circuit. The comparison of power output of the top two TEMs are shown in Figure 3. There is obvious power improvement of both two TEMs by using the aluminium plate.

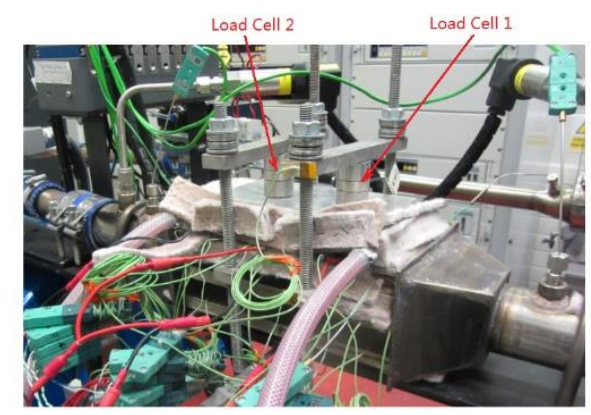

Figure 1. TEG testing in a diesel engine EGR path

The data acquisition system used in the experimental work in this study consists of NI cRIO chassis and 16bit analog input module. The maximum uncertainty of the voltage and current measurement is around $\pm 0.2 \%$. Hence the maximum uncertainty of computed electrical power is around $\pm 0.3 \%$ according to the theory of the propagation of uncertainty.

Page 2 of 12

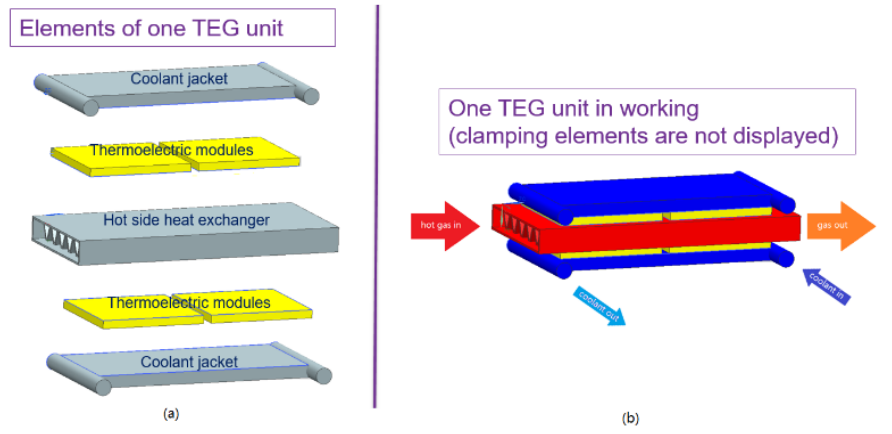

Figure 2. (a) Four TEMs and one hot side heat exchanger and two cold side exchangers; (b) TEG consisted of four TEMs in work mode

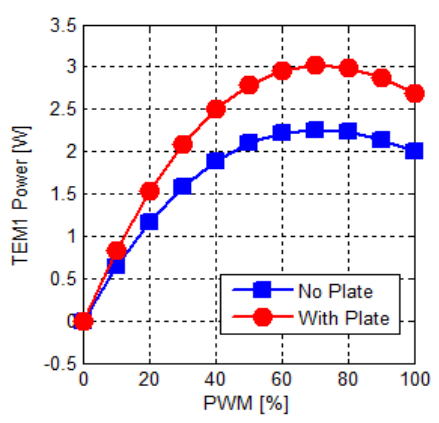

(a)

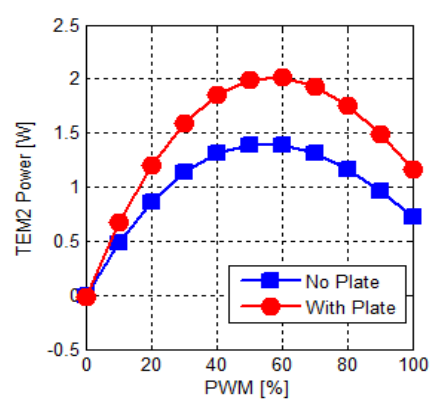

(c)

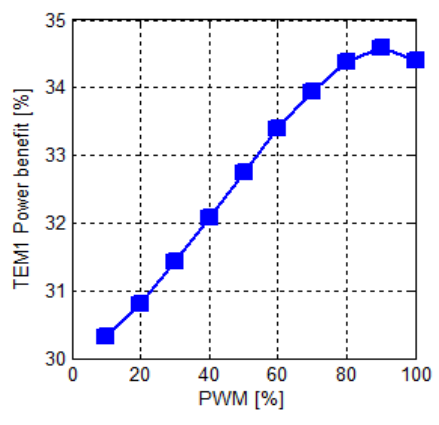

(b)

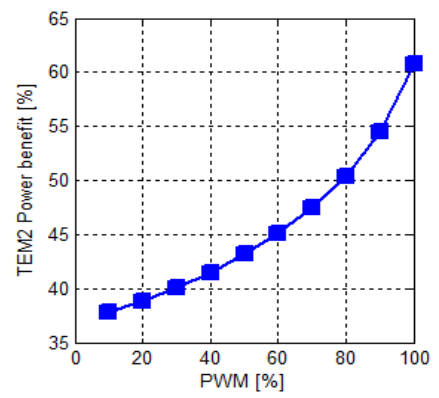

(d)
Figure 3. Test results: (a) Electrical power of the first top TEM in the upstream position; (b) increased power percentage by using aluminum plate; (c) Electrical power of the second top TEM in the downstream position; (b) increased power percentage by using aluminum plate;

\section{What is the Optimal Thickness of the Aluminum Plate?}

Now here comes a question, how much the thickness of the aluminum plate should be. Instead of repeating the experimental test with various thickness of the aluminum plate, this work was done using a STAR-CCM+ TEG model. STAR-CCM+ is an entire engineering process for solving problems involving flow (of fluids or solids), heat transfer, and stress [16]. The version of the STAR$\mathrm{CCM}+$ used in this study is 9.06. When developing the TEG model, perfect contact between each pair surface was assumed.

Figure 4 shows the temperature distribution of three cases which are 1) without aluminum plate, 2) with $1 \mathrm{~mm}$ aluminum plate and 3) with $7 \mathrm{~mm}$ aluminum plate respectively. It can be seen that there is 
changes of temperature distribution pattern among these three situations. The sampled temperatures along the middle line of the top two TEMs along the gas flow direction are depicted in Figure 5. Figure 5 plays an important role in the interpretation of the benefit from using aluminum plate and the TEG performance evolves with the thickness of the aluminum plate. When there is no aluminum plate, the temperature along the middle line of both TEMs is very curved toward lower temperature value. By using $1 \mathrm{~mm}$ aluminum, these two curves have been not only straightened but also lifted to higher value. This can be explained as the big jump thermal conductivity from stainless steel to aluminum plate of which the thermal conductivity is around $237 \mathrm{~W} / \mathrm{m}$.K. The lateral thermal conduction heat transfer has contributed to this phenomenon. When the thickness of the aluminum plate increases, the temperature of the upstream TEM tends to decrease, while the temperature of the downstream TEM tends to increase. These two lines both become more level and straight. This is also because the thicker the aluminum plate, the more lateral heat transfer from upstream to downstream.

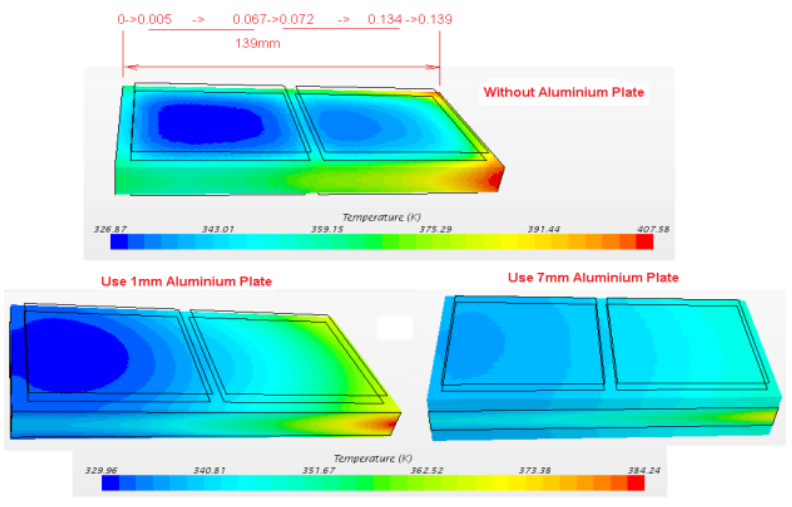

Figure 4. Top: the surface temperature distribution of the hot side heat exchanger without aluminum plate; Bottom left: the surface temperature distribution of the hot side heat exchanger using $1 \mathrm{~mm}$ aluminum plate; Bottom right: the surface temperature distribution of the hot side heat exchanger using $7 \mathrm{~mm}$ aluminum plate.

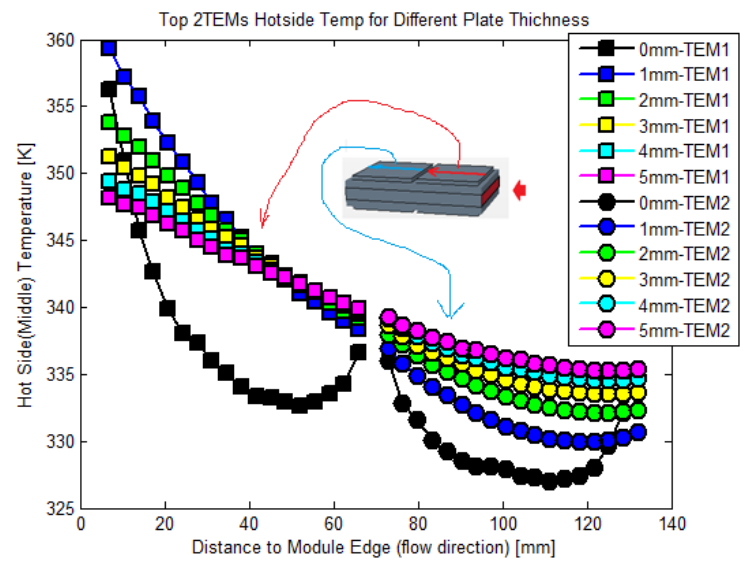

Figure 5. Temperature samples along the middle line of the TEMs along the gas flow direction

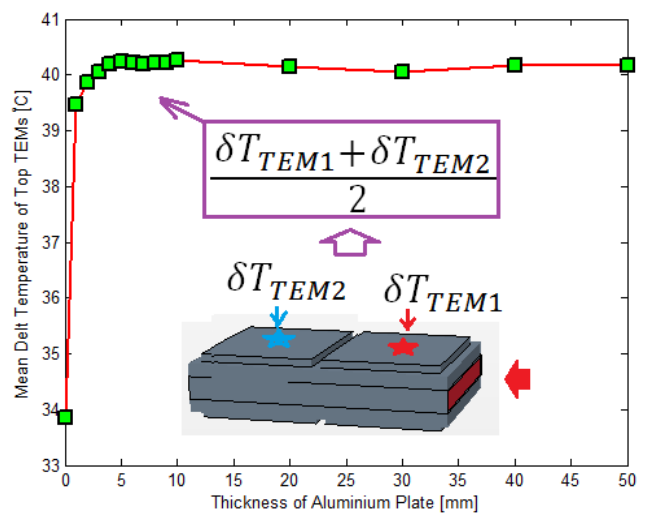

Figure 6. The average of delta temperature along the middle line of the top two TEMs varies with the thickness of the aluminum plate.

Figure 6 is the plot of average delta temperature of the hot side and the cold side of two TEMs verse the thickness of the aluminum plate. It shows that the average delta temperature reaches the plateau at $4 \mathrm{~mm}$. Similar simulation results have been obtained for other gas in conditions. This suggests that placing an aluminum plate with even only $1 \mathrm{~mm}$ thickness will help to improve the TEG output performance and that plate thickness greater than $4 \mathrm{~mm}$ provides no additional benefit. Other metal plate which has high thermal conductivity such as copper can be used in steady of aluminum plate but will add more into the cost of the TEG [17].

1D models do not include the lateral heat conduction mechanism and they are developed under the assumption that there is even temperature distribution within the contact surface area of one TEM. 2D modelling techniques like the 3D modelling techniques can be used in this simulation work.

\section{GT-Power TEG Model}

When the system level optimization and prediction work need to be carried out for the application of TEG in engine waste energy harvest, GT-Power is a good choice. No only it is convenient in modelling engine system, but also there is ready to use TEM block in the library and its strong capability in modelling the gas and coolant flow, heat exchanger thermal behavior etc.

A TEG unit model with one TEM has been built in GT-Power version 2016, See Figure 7. It is a basic unit brick for building future complete TEG device. The aim of this modelling task is to investigate the behaviour of TEG when it works under wide range of engine operating conditions, to explore the influence of TEG on engine performance and to design a model-based control system to maintain the energy balance and prevent the possible damage of the TEG. It is a dynamic TEG model which includes the dynamic of exhaust gas, thermal inertia of the TEM and heat exchanger. Hence, it can simulate the transient response of the TEG device.

Figure 7. (can be found at the end of this paper)

\section{Modelling the TEM}

A complete TEM is mainly made up by two ceramic wafers and the thermoelectric elements between them. A basic TEM unit model which consists a hot-wafer, a cold-wafer and a TEM block is shown 
in Figure 8. There is one ceramic wafer on TEM hot side and cold side respectively. Cond-Hot- 1 and Cond-Cold- 1 are used to simulate the contact thermal resistance. Air-Cond is the air gap between the ceramic wafer. TEM-1 is the block for emulating both thermal and electrical behavior of a TEM. The required input parameters for the TEM block are shown in Figure 9. These input parameters include TEM geometrical parameters and thermoelectric properties.

Unavoidably, there is properties loss during the manufacture process of a TEM. In order to have high accuracy of the TEM model, validated module based thermoelectric properties should be used in this setup.

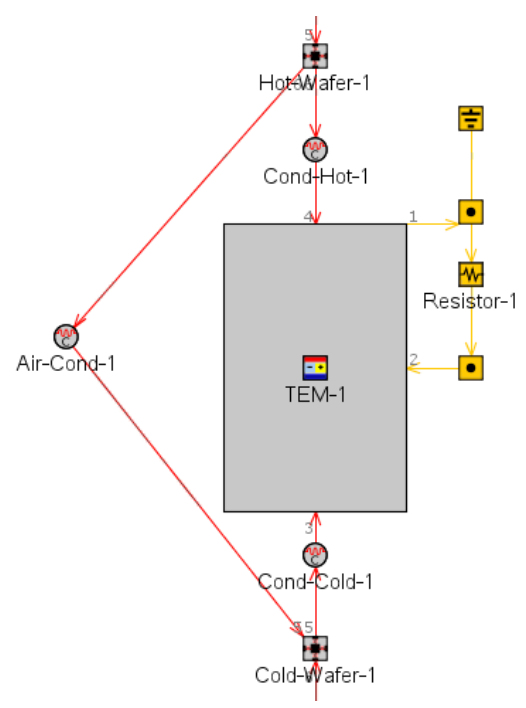

Figure 8. A unit TEM GT-Power model

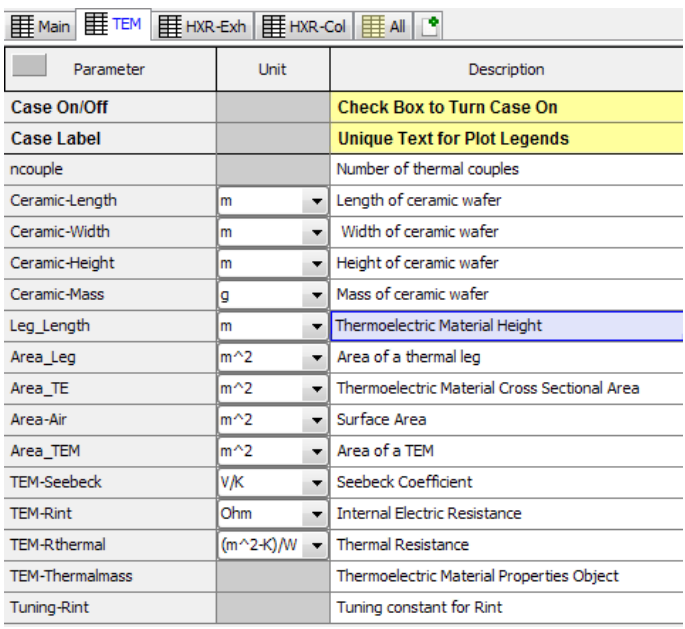

Figure 9. Setup window of input parameters for TEM Block

The main tuning parameter for the TEM model is the thermal contact conductance (Cond-Hot and Cond-Cold). Figure 10 shows the best tuned result of the TEM model to match a module performance given in the datasheet for steady state conditions.

Page 4 of 12

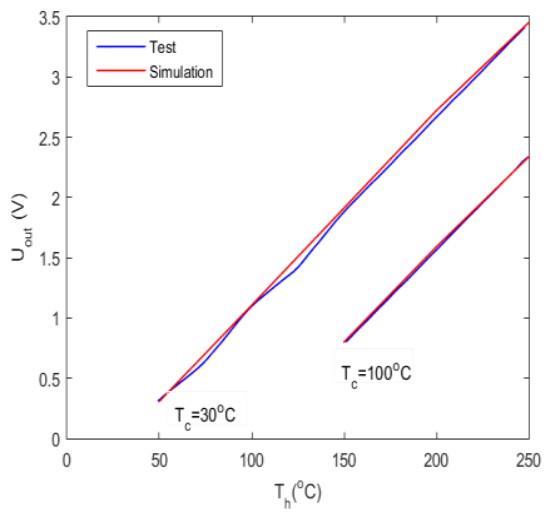

(a)

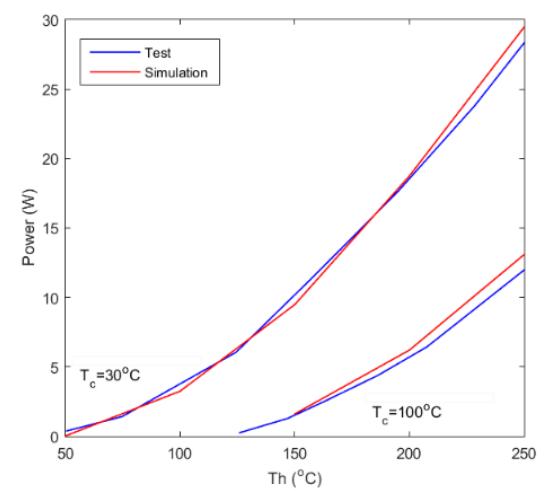

(a)

Figure 10. TEM model performance at steady state: (a) OCV; (b) Maximum electrical power

\section{Modelling the heat exchanger}

Because the TEM is closely integrated with the heat exchanger to form a TEG, the heat exchanger templates within the GT-Power do not fit the TEG scenario. So that the heat exchanger has to be modelled using pipe and thermal mass blocks. The structure of both hot side and cold side heat exchanger can be seen in Figure 7. The pipes are used to calculate the temperature and pressure along the heat exchanger. The heat transfer coefficient which is correlated to both gas flow rate and gas temperature needs to be input as known function. The validation of a TEG GT-Power model which consists multiple TEM units against engine test results is undergoing. This result together with its integration into engine model for system level optimization, prediction and control design will be discussed in another forth coming paper.

\section{Simscape TEG Model}

\section{Modelling the Engine Exhaust System}

Simscape provides a quick way to develop physical model within MATLAB/Simulink environment. The element blocks in Simscaps are very basic. Users can create their own custom component models using MATLAB based Simscape language which enables text-based authoring of physical modelling components, domains and libraries 
[18]. A model of the exhaust system of a 2 liters GTDi gasoline engine was developed using Simscape, see Figure 11. The exhaust system was divided into four segments. Each segment pipe was modelling using one internal convection heat transfer and one external convection heat transfer element. The average gas temperature within the pipe was estimated using a subsystem which is displayed in Figure 12. This subsystem also gives the estimated value for gas out temperature. Figure 13 is the diagram of this engine which was installed on a dyno engine test bed. This validation result using engine test data is displayed in Figure 14.

Figure 11. (can be found at the end of this paper)

Figure 12. (can be found at the end of this paper)

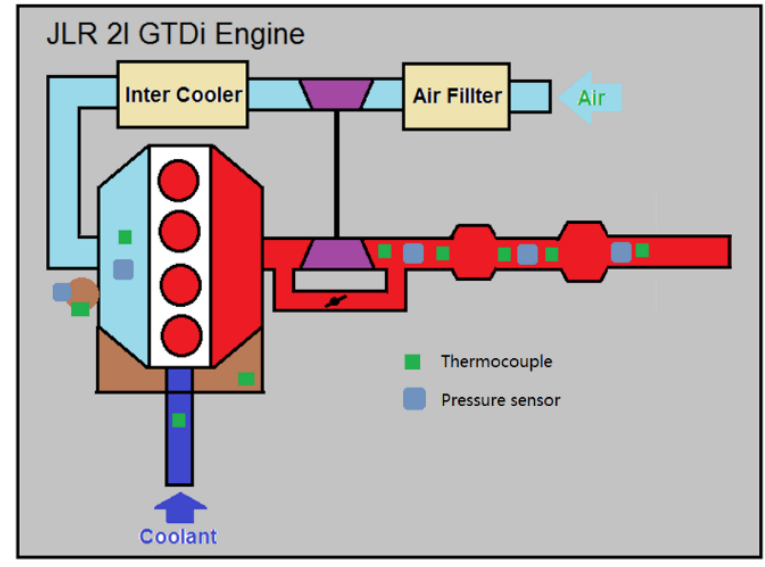

Figure 13. A diagram of the 2 liters GTDi gasoline engine

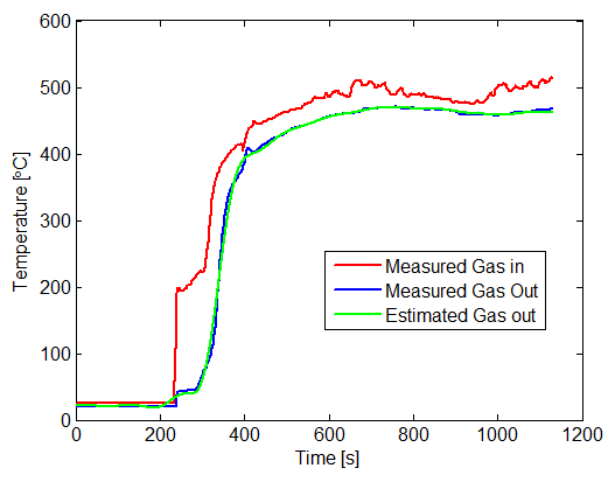

Figure 14. Validation result of the Simscape exhaust system model

\section{Prediction the Output of the TEG Mounted Directly to the External Surface of the Engine Exhaust System}

It can be seen from Figure 14 that the gas out temperature after the fourth pipe segment is still as high as $500^{\circ} \mathrm{C}$. Hence, here comes a couple of questions. The first is how is the TEG performance if the TEMs are mounted to the external surface of the exhaust pipe without change the exhaust pipe. The second is will the hot side temperature of the TEMs is over the commercial module limit which is $250^{\circ} \mathrm{C}$ ? These two questions can be answered by using the validated exhaust system Simscape model in the previous section. But before doing that, the model in Figure 11 and the subsystem in Figure 12 need to be modified to include TEM component and Peltier effect. For simplicity, Joule heat effect and Thomas effect were neglected. To further simplify the problem, only one pipe segment model was used for this simulation. Two conduction heat transfer elements ware added and to replace the external convection heat transfer element, see Figure 15. The cold side was simulated as a constant temperature source. Figure 16 shows the Peltier pumping heat transfer was extracted in computing the average gas temperature within one pipe segment.

The simulation result shows that even though the gas in temperature is very high, the hot side temperature of the TEM is very low with maximum value is at $50^{\circ} \mathrm{C}$. So that the harvested electrical energy is very low. It is because the heat transfer from gas to the exhaust pipe wall is not big enough to give high hot side temperature.

In R2016b MATLAB, there is gas system element block in Simscape , which will help to build more accurate model. However, if a dynamic TEG model which is used for predicting TEG output during an engine transient cycle is to be developed, customized heat exchanger block and customized temperature dependent TEM block need to be created first.

Figure 15 (can be found at the end of this paper)

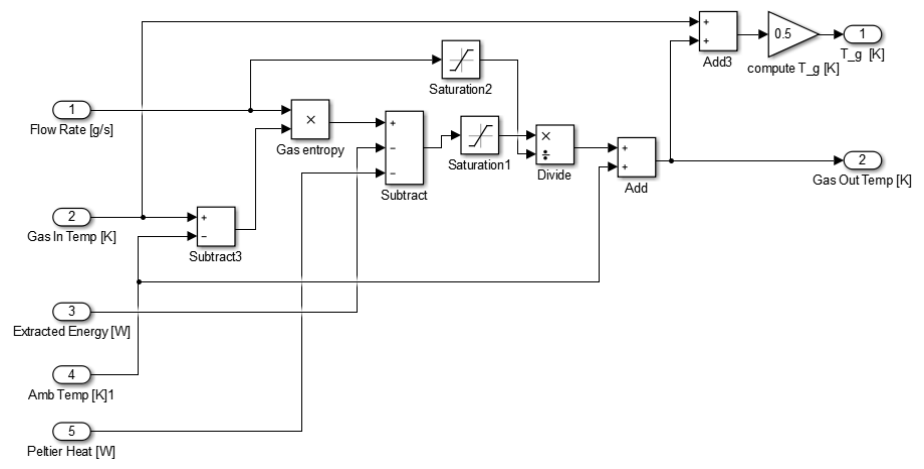

Figure 16. Subsystem for computing the average gas temperature includes the Peltier heat pumping effect.

\section{A Simulink TEG Model}

\section{Model Structure}

The physical equations about the TEM multiple mechanism have been well studied $[19,20]$. Figure 17 shows the energy flow within a TEM. The heat flow cause by Thomas effect was not included. When there is current flow through the TEM, the Peltier pumping energy developed from hot side to cold side. The Peltier pumping thermal energy into the hot side of the TEM is higher than the Peltier pumping thermal energy out the cold side of the TEM. Their difference equals to the sum of joule heating $\frac{1}{2} I^{2} R_{\text {int }}$ and electrical output power $P_{\text {ext }}$. The energy flow within a unit TEG which consist of one TEM is depicted in Figure 18. $R_{f i n}, R_{c h}, R_{c c}$ are respectively the heat exchanger thermal resistance, the hot side contact thermal resistance and the cold side thermal resistance. $m_{h x r}$ is the mass weight of the heat exchanger. $P_{\max }$ is the maximum electrical output of the TEM. Letter $Q$ represents the thermal energy and letter $T$ represents the temperature. The detailed physical equations for TEM and heat exchanger used in this modelling work can be found in reference [21].

Page 5 of 12 
A numerical dynamic TEG model was implemented using MATLAB function block within Simulink environment. Figure 19 shows the inputs that are used in computing one step hot side temperature and gas out temperature. The computation of current hot side temperature $T_{h}(i)$ was based on the four inputs which are: current gas flow rate $\dot{m}_{g}(i)$, current gas in temperature $T_{\text {in }}(i)$, current cold side temperature $T_{c}(i)$ and previous hot side temperature $T_{h}(i-1)$. Meanwhile the gas out temperature was estimated as well. As it is indicated in Figure 19, this model includes modelling the influence from the geometry of TEM and heat exchanger and the temperature dependent TEM properties and heat exchanger properties.

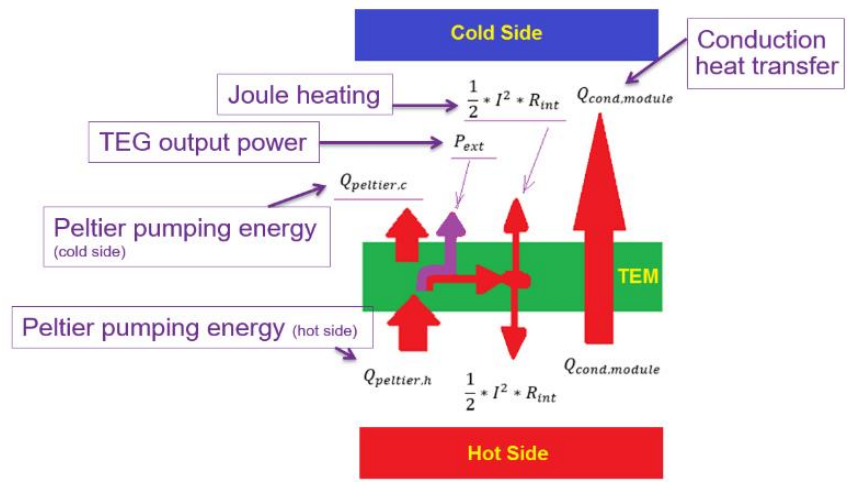

Figure 17. Energy flow within a TEM

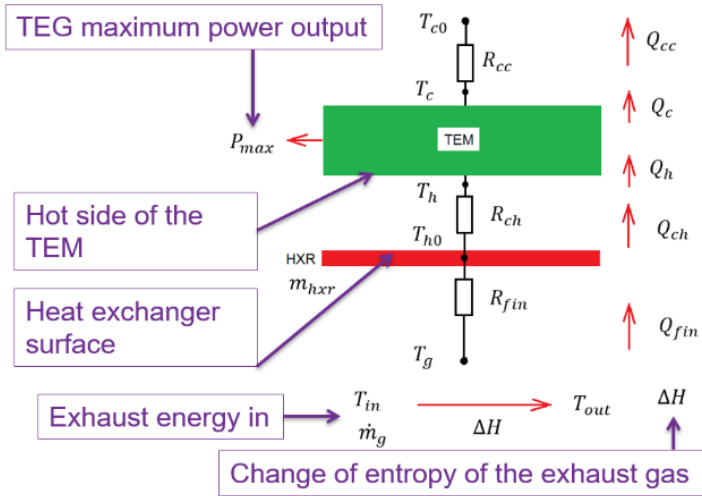

Figure 18. Energy flow within a TEG unit

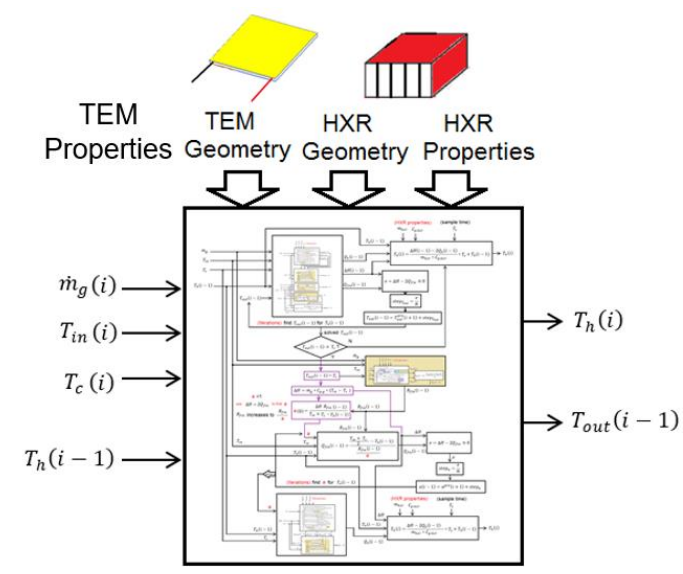

Figure 19. The inputs for computing one step hot side temperature and gas out temperature.

Page 6 of 12
Figure 20. (can be found at the end of this paper)

Figure 20 shows the structure of the heat exchanger model. The model block shown in Figure 19 was implemented using MATLAB function block in the Simulink environment, see Figure 21. The equations used in this MATLAB function are shown in Figure 22. If two TEG units are connected thermally in series, the model of this TEG device would be like that in Figure 23. The estimated gas out temperature of the first TEG unit is connected to the following TEG unit as gas in temperature. The gas flow lag along the hot side heat exchanger channel was not considered in the model. If a long TEG device is to be modelled, this lag factor has to be included in the model.

Figure 21. (can be found at the end of this paper)

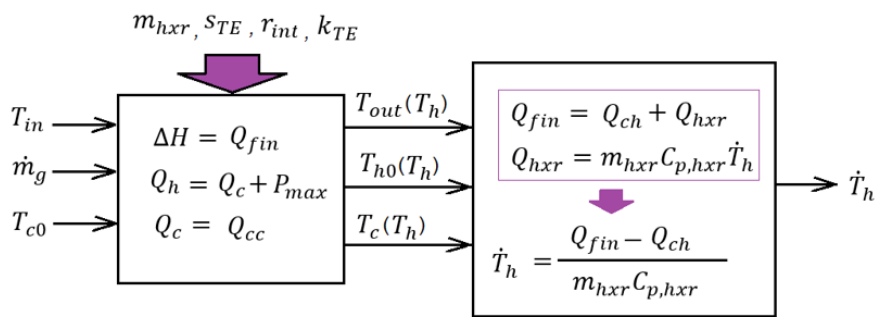

Figure 22. Equations used for solving $\mathrm{T}_{\mathrm{h}}$

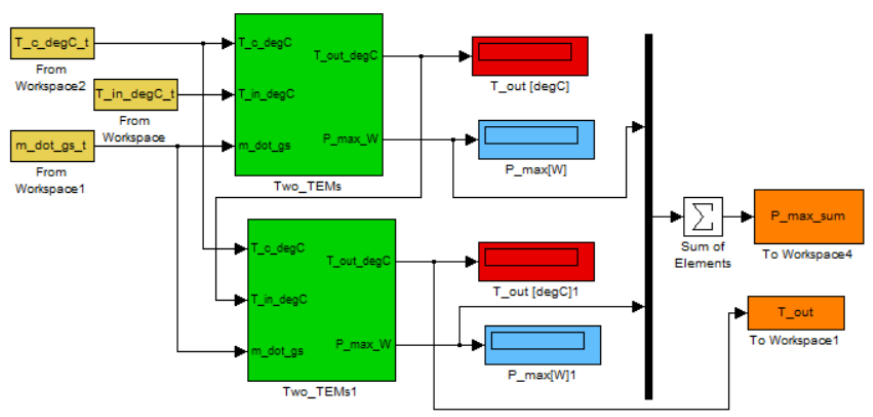

Figure 23. Two TEG units connected thermally in series

\section{Model Validation Results}

Validation results of this dynamic TEG model using an engine transient cycle data was plotted in Figure 24. Both gas out temperature and maximum electrical power output from the TEG matches well to the measured values. In Figure 24 (b), Pmax is the maximum electrical output power of the two modules using Maximum Power Point Tracking (MPPT) technique during the transient testing. 


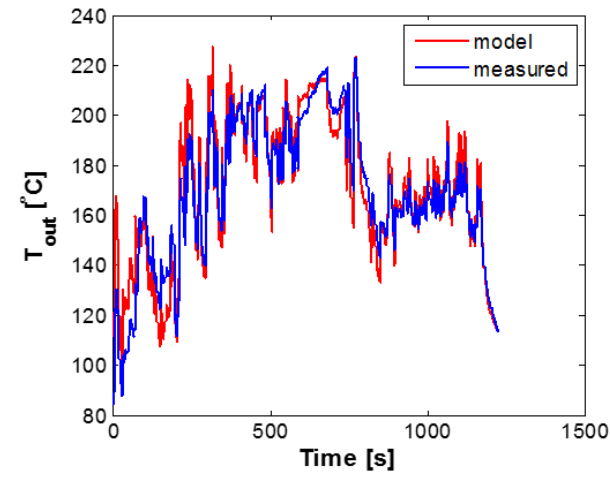

(a)

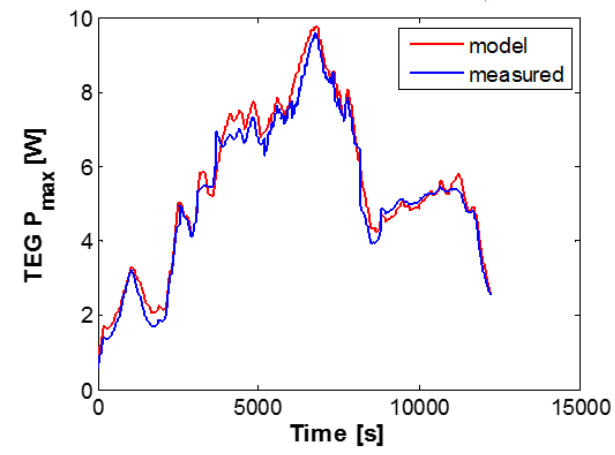

(b)

Figure 24. Validation results using engine test results: a NETC transient cycle. (a) Gas out temperature of the TEG; (b) Maximum electrical power output from the TEG.

\section{The Impact of Thermal Inertia on TEG Performance}

This model then was used in the study of the impact of thermal inertia on the mean of maximum power output of a TEG device for an engine transient cycle. Will the TEG performance benefit from having big thermal inertia? The possible physical sources for mass increases can be either heat exchanger or heat spreader, or both.

Six mass weight conditions were selected for this simulation work which is from $0.01 \mathrm{~kg}$ up to $0.11 \mathrm{~kg}$ with $0.02 \mathrm{~kg}$ as step size. This is the mass for one TEG unit. The sum of maximum power output of the TEG device for these 6 conditions were plotted together in Figure 25 . The transient gas input condition is from an engine test during a NEDC transient cycle. The zoomed part in Figure 25 clearly shows that larger thermal inertia suppresses the fluctuation caused by the fluctuation of gas in condition which is quite understandable. However, the plot in Figure 26 shows that the average of maximum electrical power output during the cycle decreases with bigger mass weight. But the reduction is of mean maximum power is quite small which is about $9.4 \mathrm{~W} / \mathrm{kg}$. This implies that the thermal inertia is not so critical in a TEG device. The performance of TEG device does not benefit from a large inertia design.

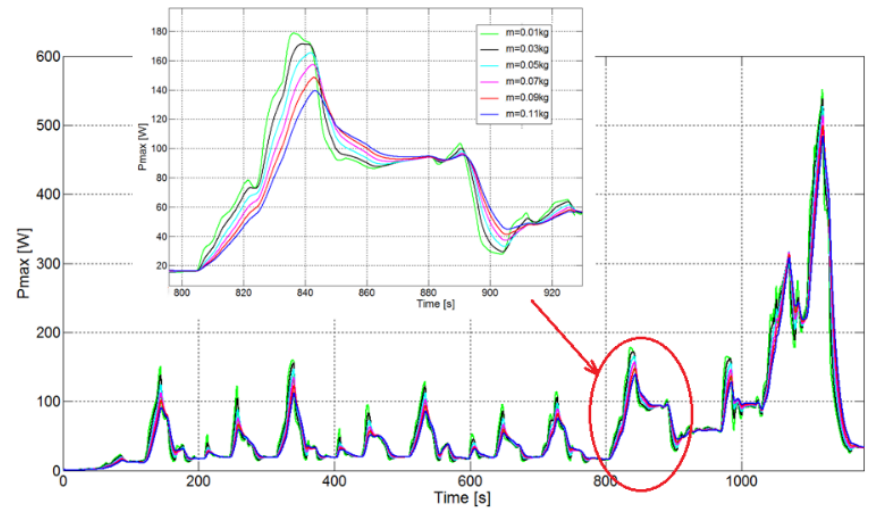

Figure 25. Predictions of a TEG output under different thermal inertia conditions for an engine during a NEDC cycle.

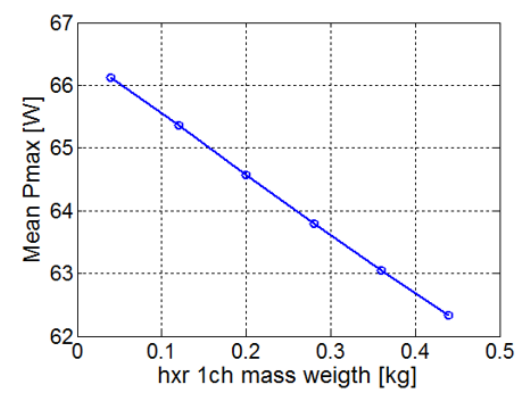

Figure 26. Mean maximum electrical power output of a TEG device varies with thermal inertia.

\section{Summary/Conclusions}

Four modelling techniques which are 3D CFD, GT-Power, Simscape and MATLAB function have been used in modeling TEG device. CFD TEG model was used to find out that only a thin aluminum plate can make the temperature distribution much even between the contact surface of a TEM to the hot side heat exchanger. The GT-Power software provides a TEM template block which allows setting temperature dependent model properties. However, the existing heat exchanger template does not fit for TEG application. The correlation for heat transfer coefficient has to be input manually. Since the GTPower is popular in modelling automotive engine, GT-power TEG model can be seamlessly integrated with engine model and then be used for system level optimization. Simscape provides a very efficiency way to develop physical model. However, so far the existing element blocks are not enough for dragging and connecting procedure for TEG model. Users have to develop TEM and heat exchanger custom blocks using Simscape language. Learning Simscape language needs a lot of effort. A validated Simscape model of an engine exhaust system was used to predict the TEG output when there is no modification of the exhaust pipe. It was found that the performance of such TEG device is too poor. A dynamic TEG model has been developed using MATLAB function block in the Simulink environment. It has good validation results against engine transient test data. This model then was used to investigate the impact of thermal inertia on the mean power output for a transient cycle. The conclusion is the TEG performance is not very sensitive to thermal inertia. Big thermal inertia does not help increase the average TEG output. 


\section{References}

1. Stobart, R., Milner, D., "The Potential for Thermo-Electric Regernation of Energy in Vehicles", SAE Technical Paper 2009-01-1333, doi: 10427/2009-01-1333.

2. Arsie, I., Cricchio, A., Marano, V., Pianese, C., et al., "Modeling Analysis of Waste Heat Recovery via Thermo Electric Generators for Fuel Economy Improvement and CO2 Reduction in Small Diesel Engines", SAE Int. J. Passeng. Cars-Electron, Electr. Syst. 7(1):2014, doi: 10.4271/2014-01-0663.

3. Meda, L., Romzek, M., Zhang, Y., and Cleary, M., "Development of a $1 \mathrm{~kW}$ Exhaust Waste Heat Thermoelctric Generator," SAE Int. J. Commer, Veh. 9(1):2016, doi:10.4271/2016-01-1273.

4. Langley, J., Taylor, M., Wagner, G., and Morris, S., "Thermoelectric Energy harvesting from Small Aircraft Engines", SAE Technical Paper 2009-01-3093, doi: 10427/2009-01-3093.

5. D. Crane and J. Lagrandeur, "Progress Report on BSST-Led US Department of Energy Automotive Waste Heat Recovery Program", Journal of Electronic Materials, Vol. 39, No. 9, 2010, DOI:10.1007/s11664-009-0991-0.

6. D. Crane, J. Lagrandeur, V. Jovovic, M. Ranalli, M. Adldinger, E. Poliquin, J. Dean, D. Kossakovski, B. Mazar and C. Maranville, "TEG On-Vehicle Performance and Model Validation and What It Means for Further TEG Development", Journal of Electronic Materials, Vol. 42, No. 7, 2013, DOI:10.1007/s1664-012-2327-8

7. F. Frobenius, G. Gaiser, U. Rusche and B. Weller, "Thermoelectric Generators for the Integration into Automotive Exhaust Systems for Passenger Cars and Commericial Vehicles, Journal of Electronic Material, DOI:10.1007/s11664-015-4059-Z

8. J. Bass, N. Elsner and F. Leavitt, "Performance of the $1 \mathrm{~kW}$ Thermoelectric Generator for Diesel Engines", The International Conference on Thermoelectrics, 1994, Kansas City, Kansas, USA

9. L. Meda, M. Romzek, Y. Zhang and M. Cleary, "Development of a $1 \mathrm{~kW}$ Exhaust Waster Heat Thermodelectric Generator", SAE 2016-01-1273, DOI:10.4271/2016-01-1273

10. Moumouni, Y., Baker, R. J., "Concise Thermal to Electrical Parameters Extraction of Thermoelectric Generator for SPICE Modeling", Proceedings on 2015 IEEE $58^{\text {th }}$ Midwest Symposium on Circuits and Systems, Pages: 1-4, doi: 10.1109/MWSCAS.2015.7282014.

11. Chen, M., et al., "Transient Behavior Study of Thermoelectric Generators through an Electric-thermal Model Using SPICE," Proc of $25^{\text {th }}$ International Conference on Thermoelectrics, Vienna, Aug. 2006, page 214-219.

12. Vlach, R., "Novel Approach to Thermoelectric Generator Modeling as Energy Harvesting System", Proceedings of the $16^{\text {th }}$ International Conference on Mechatronics, 2014, Pages: 725-728, doi: 10.1109/MECHATRONIKA.2014.7018352.

13. Hussain, Q. E., Brigham, D. R., and Maranville, C. W., "Thermoelectric Exhaust Heat Recovery for Hybrid Vehicles", SAE Technical Paper 2009-01-1327, doi: 10427/2009-01-1327.

14. Matsumoto, M., Morin, M., Haraguchi, T., Ohtani, M. et al., "Development of State of the Art Compact and Lightweigth Themoelectric Generator Using Vacuum Space Structure," SAE Int. J. Engines 8(4):2015, doi:10.4271/2015-01-1691.

15. Mori, M., Yamagami, T., Oda, N., Hattori, M. et al., "Current Possibilities of Thermoelectric Technology Relative to Fuel Economy," SAE Technical Paper 2009-01-0170, doi: 10427/2009-01-0170.

16. CD-adapco, "On-Line STAR-CCM+ Help”, Version 9.06
17. D. Brennan, R. Gilchrist and B. Wicksteed, Heat exchanger design and analysis for an automotive thermoelectric generator, Vehicle Thermal Management Systems Conference Proceedings, Coventry TechnoCentre, UK, 15-16 May 2013

18. Mathwork, "Simscape Language Guide", MATLAB/Simulink, R2016b.

19. Kumar, S., Heister, S. D., Xu, X., and Salvador, J. R., et al., "Thermoelectric Generators for Automotive Waste Heat Recovery System Part I: Numerical Modeling and Baseline Model Analysis," Journal of Electronic Materials, April 2013, Volume 42, Issue 4, pp 665-674, doi:10.1007/s11664-013-2719.

20. Crane, D., Jackson, G. and Holloway, D., "Towards Optimization of Automotive Waste Heat Recovery Using Thermoelectrics", SAE Technical Paper 2001-01-1021, doi: 10427/2001-01-1021.

21. Yang, Z., Winward, E., Lan, S. and Stobart, R., "Optimization of the Number of Thermoelectric Modules in the Thermoelectric Generator for a Specific Engine Drive Cycle," SAE Technical Paper 2016-01-0232, doi: 10427/2016-01-0232.

\section{Contact Information}

Zhijia Yang, Aeronautical \& Automotive Engineering Department, Loughborough University, z.yang2@1boro.ac.uk

Song Lan, Aeronautical \& Automotive Engineering Department, Loughborough University, s.lan@lboro.ac.uk

Richard Stobart, Aeronautical \& Automotive Engineering Department, Loughborough University, r.k.stobart@lboro.ac.uk

Edward Winward, Aeronautical \& Automotive Engineering Department, Loughborough University, r.e.t.b.winward@1boro.ac.uk

Rui Chen, Aeronautical \& Automotive Engineering Department, Loughborough University, r.chen@lboro.ac.uk

Iain Harber, Aeronautical \& Automotive Engineering Department, Loughborough University, i.harber@lboro.ac.uk

\section{Acknowledgments}

The authors would like to gratefully acknowledge the UK Engineering and Physical Sciences Research Council (EPSRC) for funding this research work under Grant Number: EP/K026658/1. The authors would also like to thank Graham Smith, Iain Harber, Dominic Mckean and Steve Horner from Powertrain Lab in Loughborough University for their strong support to the engine experimental setup and engine testing.

\section{Definitions/Abbreviations}

EGR

Exhaust Gas Recirculation

MPPT

Maximum Power Point

Tracking

MVEM

Mean Value Engine Model

Page 8 of 12

$10 / 19 / 2016$ 
Thermoelectric Generator

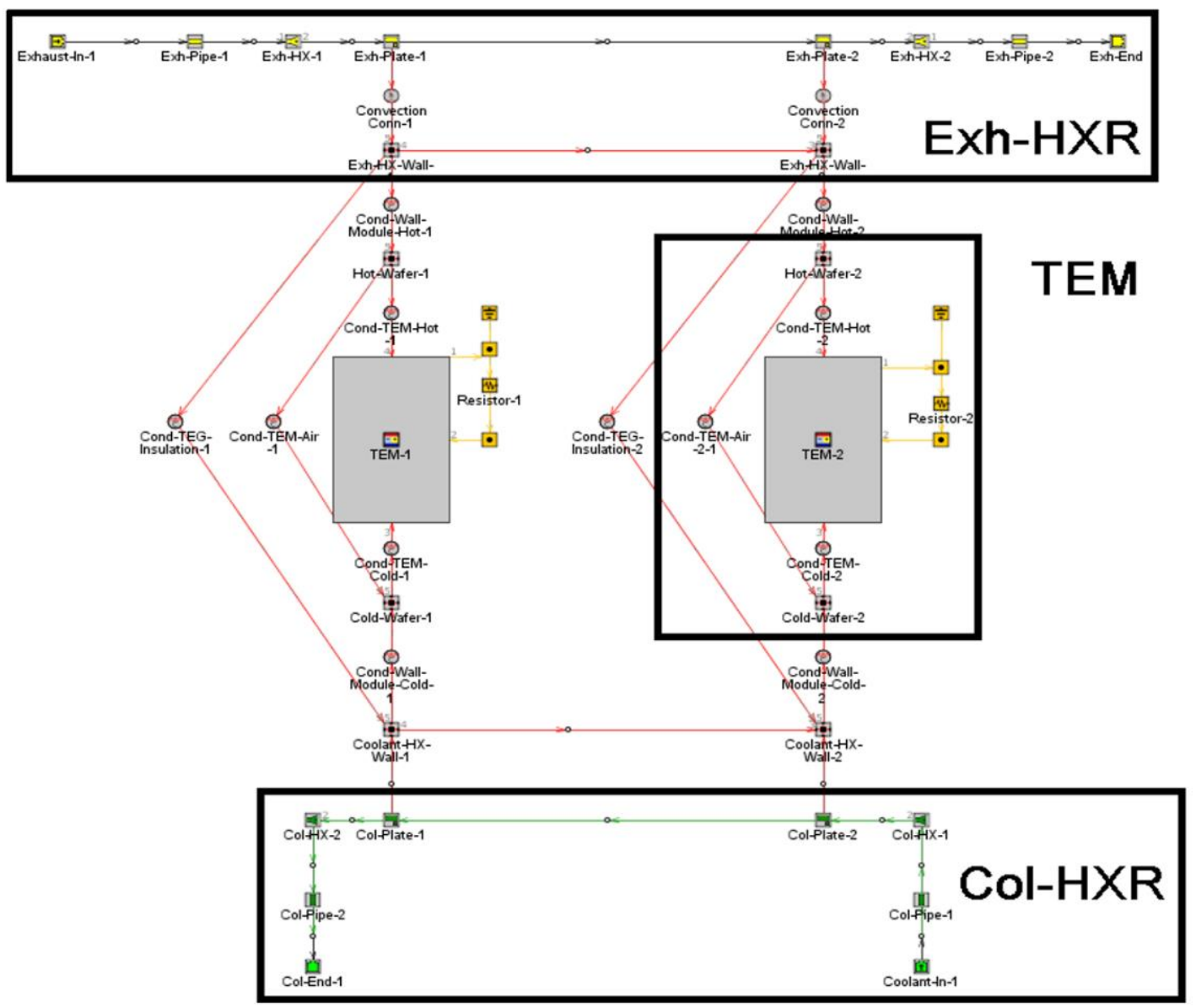

Figure 7. One unit TEG model with one TEM 


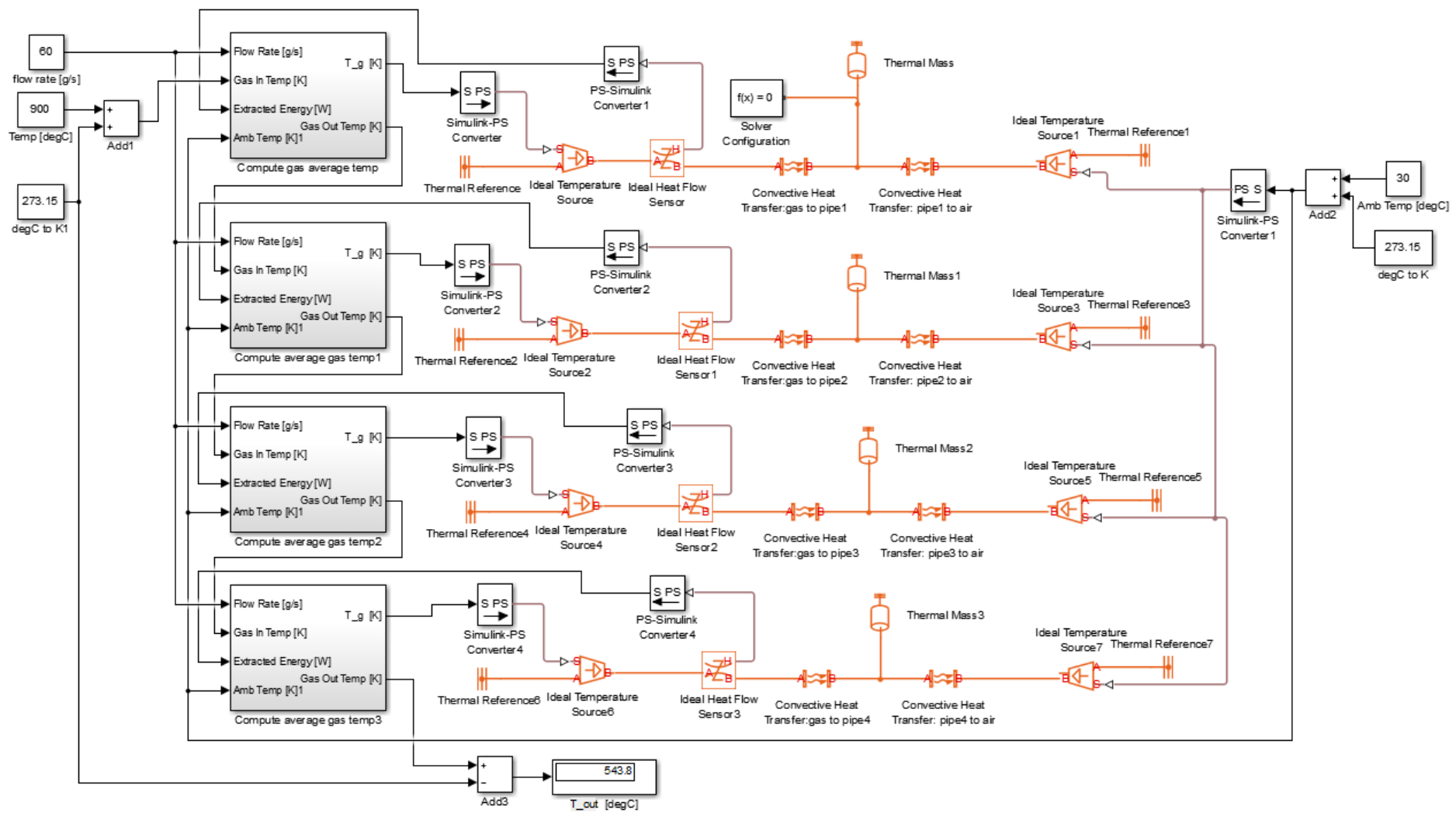

Figure 11. A Simscape engine exhaust system model

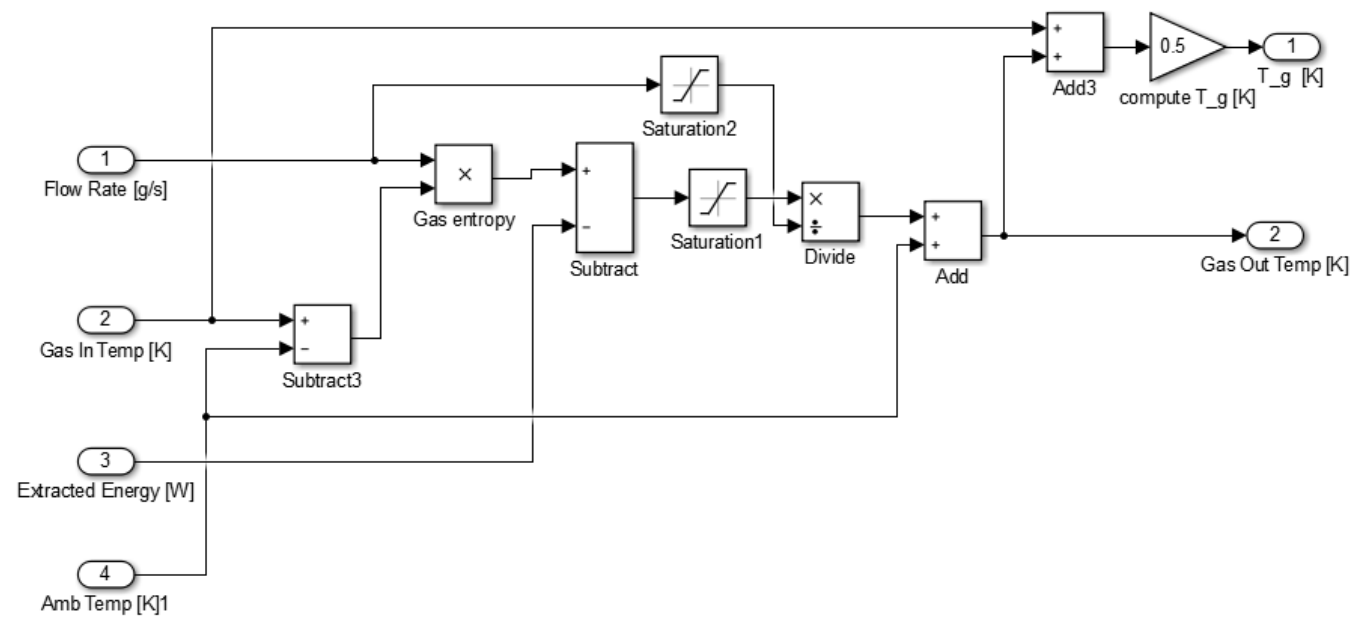

Figure 12. Subsystem for computing the average gas temperature 


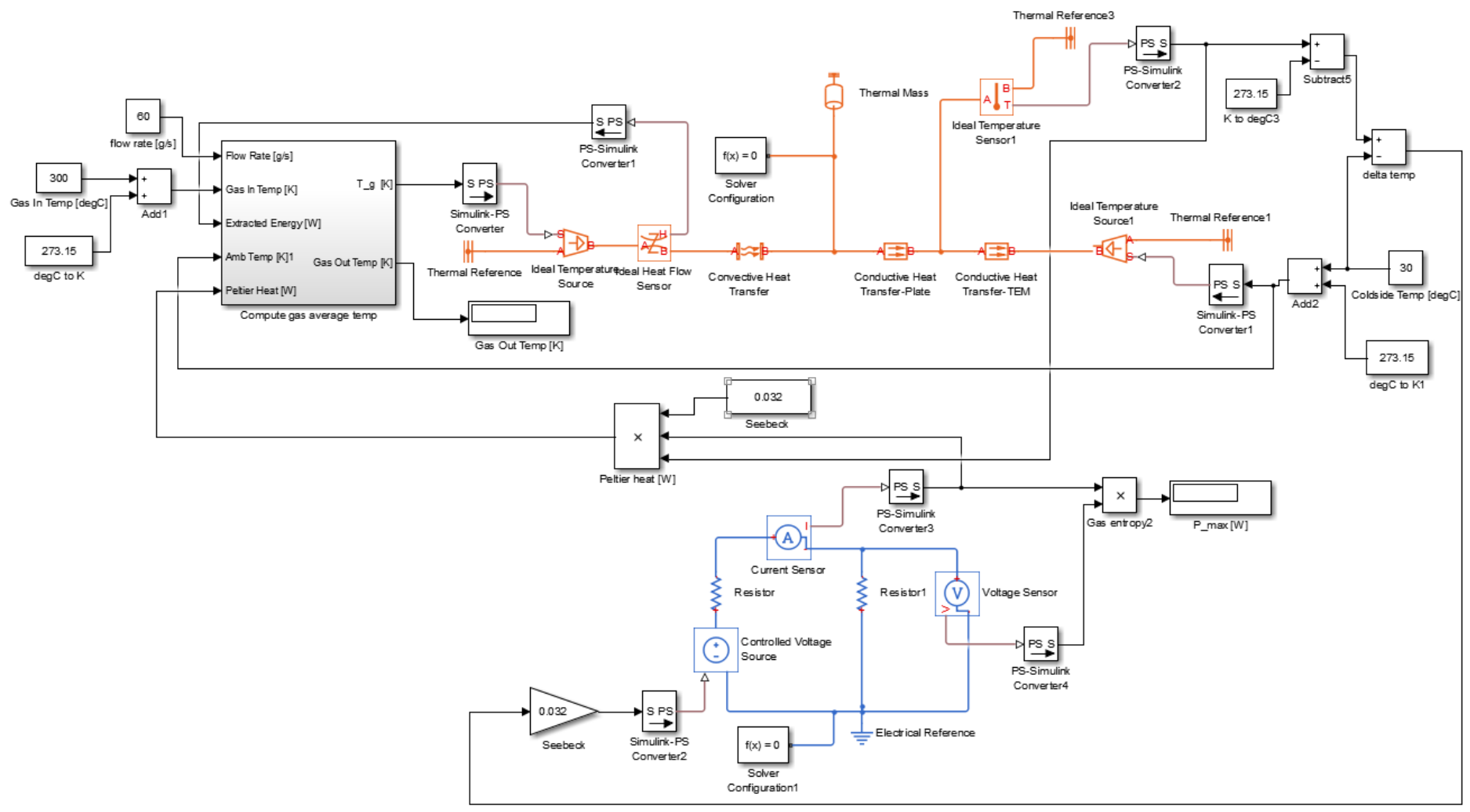

Figure 15 The first pipe segment model including the TEMs mounted on the surface

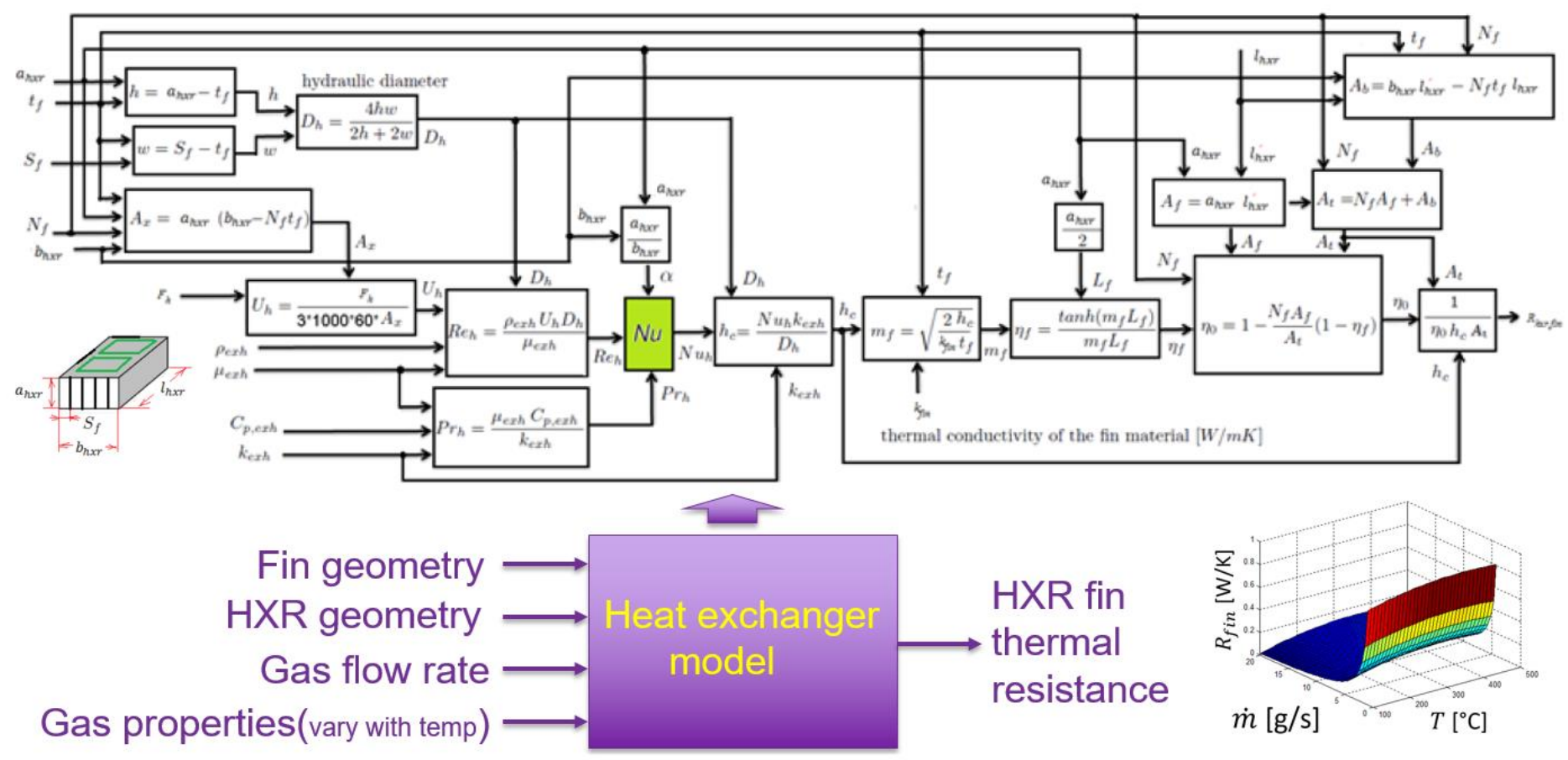

Figure 20. Heat exchanger model

Page 11 of 12 


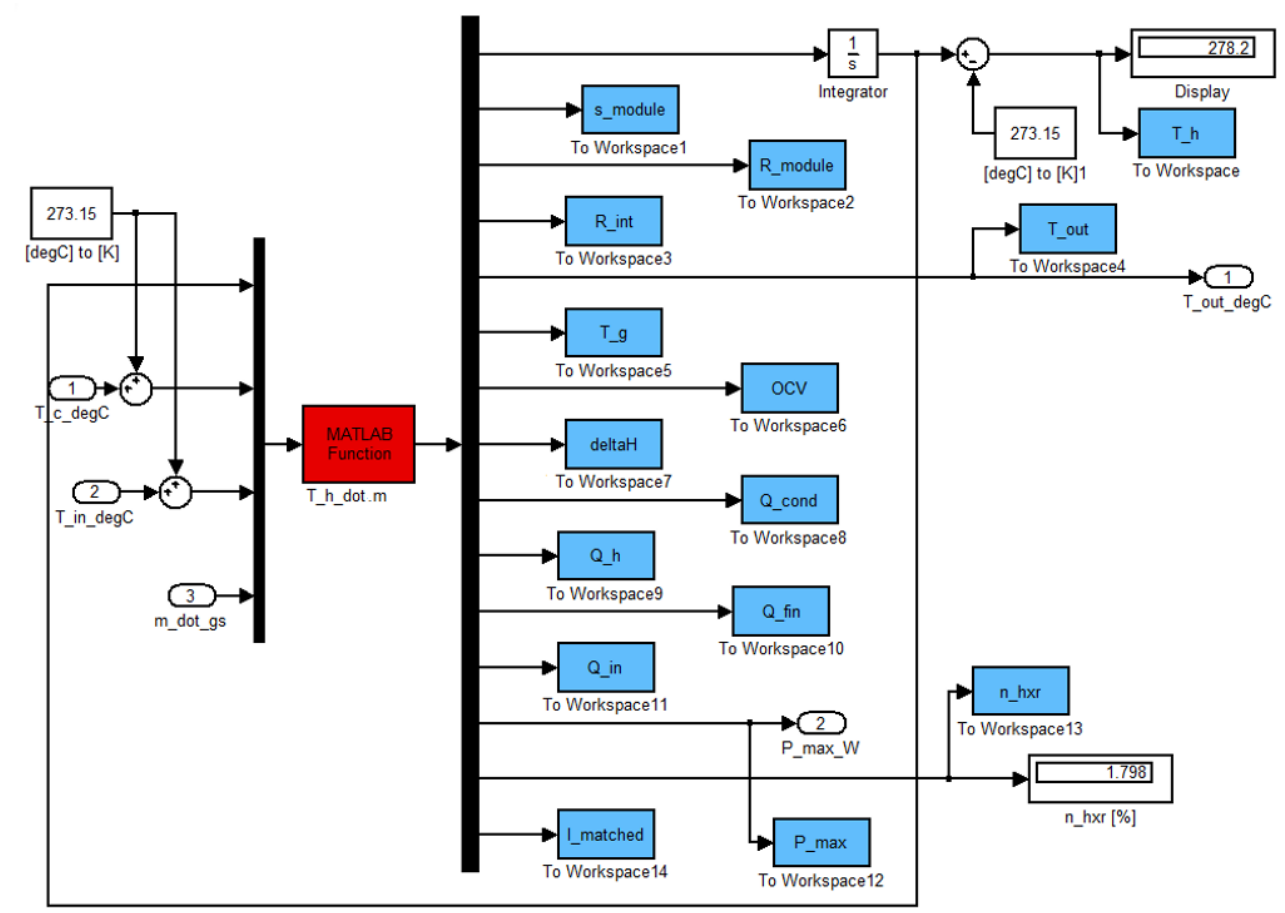

Figure 21. Implementation of unit TEG dynamic model using MATLAB function block. 